\title{
A aprendizagem em tempos de Homo œconomicus cyber
}

\author{
The learning in times of Homo oeconomicus cyber \\ La aprendizaje en tiempos de Homo œeconomicus cyber
}

ELISÂNGELA BARBOSA MADRUGA (Da

PAULA CORRÊA HENNING Db

\section{Resumo}

Este artigo discute o cenário discursivo da atualidade no que tange a constituição de sujeitos por meio das tecnologias na educação formal, especificamente, os jogos eletrônicos. Sob esse viés as demandas sociais e econômicas são atendidas para garantir um amanhã ambientalmente responsável e próspero. Nessa perspectiva, considerando a realização de alguns tensionamentos acerca do tema, tomou-se como objetivo de pesquisa a identificação e análise dos ditos que são assumidos por professores da escola primária e reproduzidos em planos de aula. Treze planos de aula para crianças de 6 a 7 anos, produzidos por professores no jogo eletrônico Minecraft: Education Edition foram escolhidos como material de análise. Para a análise dos ditos utilizou-se como proposta teórico-metodológica a análise do discurso foucaultiana. Ao analisar os planos, verificouse que 7 lições visavam uma aprendizagem baseada em projetos para desenvolver habilidades como colaboração, criatividade, pensamento crítico etc. Os planos abrangeram os anos 2016, 2017 e 2018. A análise discursiva apontou para a constituição de um sujeito proativo, dinâmico e flexível que se fundamenta num pensamento neoliberal, computacional e científico para a resolução de futuras situações problemas, entre elas as provocadas por uma crise ambiental.

Palavras-chave: Educação. Educação Ambiental. Minecraft. Michel Foucault.

\section{Abstract}

This article discusses the current discursive scenario in what refers to the constitution of subjects through technologies in formal education, specifically, electronic games. Under this bias, social and economic demands are answered to ensure an environmentally responsible

\footnotetext{
a Universidade Federal do Rio Grande (FURG), Rio Grande do Sul, RS, Brasil. Mestra em Educação Ambiental, e-mail: elisangelamadruga@outlook.com

b Universidade Federal do Rio Grande (FURG), Rio Grande do Sul, RS, Brasil. Doutora em Educação, e-mail: paula.c.henning@gmail.com
} 
and prosperous tomorrow. In this perspective, considering the realization of some tensions about the theme, it was taken as objective of research the identification and analysis of the sayings that are assumed by teachers of the primary school and reproduced in lesson plans. 13 lesson plans for children ages 6 to 7, produced by teachers in the electronic game Minecraft: Education Edition, were chosen as an analysis material. For the analysis of the sayings the analysis of the foucaultian discourse was used as theoretical-methodological proposal. In analyzing the plans, it was verified that 7 lessons aimed at a project-based learning to develop skills such as collaboration, creativity, critical thinking, etc. The plans covered the years 2016, 2017 and 2018. The discursive analysis pointed to the constitution of a proactive, dynamic and flexible subject that is based on neoliberal, computational and scientific thinking for the resolution of future situations, such as those caused by an environmental crisis.

Keywords: Education. Environmental Education. Minecraft. Michel Foucault.

\section{Resumen}

Este artículo discute el escenario discursivo de la actualidad en lo que se refiere a la constitución de sujetos por medio de las tecnologías en la Educación formal, específicamente, los juegos electrónicos. Bajo este sesgo, las demandas sociales y económicas son atendidas para garantizar un mañana ambientalmente responsable y próspero. En esta perspectiva, considerando la realización de algunos tensamientos acerca del tema, se tomó como objetivo de investigación la identificación y análisis de los dichos que son asumidos por profesores de la escuela primaria y reproducidos en planes de clase. 13 planes de clase para niños de 6 a 7 años, producidos por profesores en el juego electrónico Minecraft: Education Edition, fueron elegidos material de análisis. Para el análisis de los dichos se utilizó como propuesta teórico-metodológica el análisis del discurso foucaultiana. Al analizar los planes, se verificó que 7 lecciones tenían como objetivo un aprendizaje basado en proyectos para desarrollar habilidades como la colaboración, la creatividad, el pensamiento crítico, etc. Los planes abarcaron los años 2016, 2017 y 2018. El análisis discursivo apuntó a la constitución de un sujeto proactivo, dinámico y flexible que se fundamenta en un pensamiento neoliberal, computacional y científico para la resolución de futuras situaciones problemas, entre tales, las provocadas por una crisis ambiental.

Palabras clave: Educación. Educación ambiental. Minecraft. Michel Foucault.

\section{Introdução}

Vive-se num tempo de avanços tecnológicos que passam por áreas de conhecimento como a saúde, o ambiente, a educação, entre outras. Aprende-se e ensina-se por meio de diversas tecnologias, assim sujeitos e sociedades são moldados 
e transformados por um mundo cada vez mais virtual. Nesse panorama os discursos de crise aparecem sob o arcabouço de diversas vozes legitimadas para reforçar a importância do uso das tecnologias, principalmente, na educação (LOUREIRO, 2013).

A escola e as tecnologias assumem a responsabilidade de formar o futuro cidadão que gerenciará as cidades inteligentes do amanhã. E gerenciar o porvir nessa perspectiva também implica em saber as novas estratégias para cuidar do meio ambiente. A fabricação de humanos œconomicus (FOUCAULT, 2008) cybers dentro dessa conjuntura de virtualização de mundos, crises ambientais e educacionais, temse tornado tema relevante na atualidade.

Ao interrogar as contingências desse tempo, toma-se como objetivo desta pesquisa a identificação e análise dos ditos que são assumidos por professores da escola primária e reproduzidos em planos de aula por eles elaborados, para constituir estudantes com habilidades desejadas para este tempo. Tais planos fazem parte do acervo de lições do website do jogo eletrônico para educação, Minecraft: Education Edition, que é produzido pela empresa Microsoft. O site do jogo é "uma plataforma colaborativa e versátil que os educadores podem usar em todos os assuntos para incentivar as habilidades do século XXI" (MINECRAFT, s/d).

A pesquisa selecionou 13 planos de aula destinados as idades de 6 a 7 anos, referentes ao tema meio ambiente, que foram produzidos por professores de países diferentes. Optou-se por tal recorte em virtude da emergência de se falar e ensinar sobre a crise ambiental da atualidade.

Basta olharmos as preocupações econômicas, sociais, políticas, culturais e ambientais voltadas para a crise do meio ambiente que se tornam pauta importante em diferentes instâncias da sociedade. Um exemplo de tal força e importância são os grandes encontros mundiais que têm como foco a questão da Crise Ambiental, tais como a recente $\mathrm{RIO}+20$, que ocorreu no Rio de Janeiro, em 2012 e a COP 20, em novembro de 2014, em Lima, Peru. Em torno da fabricação do dispositivo da EA há uma produção de saberes que colocam em funcionamento relações de força, subjetivando os sujeitos a certas práticas ambientalmente "necessárias" e "corretas". Assim, um determinado modo de ser "sujeito" é produzido no dispositivo da EA - o cidadão educado ambientalmente (GARRÉ; HENNING, 2015, p. 59). 
Nessa conjuntura discursos e ditos circulam pelo âmbito social anunciando a necessidade de uma mudança urgente do comportamento humano no que se refere às problemáticas do meio ambiente. Por isso, entende-se os planos que tratam do meio ambiente como importantes produtos escolares que ensinam e educam ambientalmente o modo de se comportar frente as questões relacionadas ao meio ambiente. Sendo assim, a análise trata do que é dito e pronunciado nos planos de aula, toma-se como proposta metodológica alguns dos conceito-ferramentas da análise do discurso desenvolvido por Michel Foucault (2015). Utiliza-se a referida análise para perceber as recorrências dos ditos que estão localizados dentro de um determinado espaço discursivo (FOUCAULT, 2015). Ao que se refere a presente pesquisa, tais ditos parecem atravessar o discurso pedagógico, discurso ambiental e o discurso tecnológico. Nesta proposta, mapeiam-se no nível da existência das palavras, produções de textos, de falas, de coisas proferidas ou escritas, os ditos sobre o sujeito escolarizado.

Isso significa que é preciso trabalhar arduamente com o próprio discurso, deixando-o aparecer na complexidade que lhe é peculiar. [...] Trata-se de um esforço de interrogar a linguagem - o que efetivamente foi dito - sem a intencionalidade de procurar referencias ou fazer interpretação reveladoras de verdades e sentidos reprimidos (FISCHER, 2012, p. $74 ; 80)$.

Operar por meio da análise do discurso numa perspectiva foucaultiana é situar as coisas ditas em espaços discursivos, extrair alguns ditos, colocá-los em relação a outros, de campos iguais ou distintos (FOUCAULT, 2015). Após extrair, faz-se o agrupamento das recorrências apontando as particularidades dos ditos existentes no material.

Os planos de aula possuem uma abordagem interdisciplinar e para múltiplas faixas etárias, assim mesmo sendo destinados a crianças de 6 a 7 anos, o que corresponde o primeiro ciclo do fundamental no Brasil, podem ser adaptados para outras dos demais anos. O material é produzido por professores colaboradores e fica disponível para qualquer pessoa, pois é de livre acesso. Por tratar-se de um site americano, a plataforma se encontra em inglês, mas devido à ferramenta de tradução do próprio navegador os planos podem ser acessados em português. 
Para a organização das discussões, o artigo seguirá a seguinte estrutura: primeiro, apresenta-se o esboço teórico que embasa a pesquisa, no qual se discorre sobre o Homo œconomicus e as condições de emergência do Homo aconomicus cyber neste tempo. Em um segundo momento, elenca-se alguns ditos que reforçam uma rede discursiva. Rede que utiliza muitas estratégias tecnológicas e midiáticas, em especial do jogo Minecraft, para propagar verdades que capturam muitos sujeitos. Em seguida expõem-se as análises e os resultados do material eleito.

\section{O Homo œeconomicus cyber e os discursos que o circundam}

O filósofo Michel Foucault no curso ministrado em 1978-1979 no Collège de France, O nascimento da biopolítica, apresenta o conceito de Homo xconomicus. Em uma análise mais contemporânea, o autor estuda os sistemas econômicos neoliberais, da Alemanha e dos Estados Unidos, e aponta as condições de possibilidade para um sistema neoliberal moderno. Loureiro e Lopes (2015), ao apresentarem as problematizações de Foucault sobre os aspectos do neoliberalismo americano, comentam que ele demonstra que o modelo de sujeito de interesse dessa racionalidade política é o Homo xconomicus, que na teoria liberal clássica era o homem da troca. No bojo da racionalidade neoliberal encontram-se os sujeitos como empresários de si mesmo sob a régia da Teoria do Capital Humano, produzida pela Escola de Chicago, que tem como um dos seus principais representantes Theodore Schultz. Para Foucault (2008), a questão do neoliberalismo consiste em saber como se pode conduzir o exercício global do poder político conforme os preceitos basilares de uma economia de mercado. Trata-se assim, afirma o autor, de relacionar, de assumir como referência, de projetar em uma arte geral de governar, os preceitos basilares formais de uma economia de mercado.

Nessa organização, os sujeitos tornam-se empresários de si por meio da produção e do investimento em capital humano. Nas palavras de Foucault (2008, p. 311),

O homo œconomicus é um empresário, e um empresário de si mesmo. Essa coisa é tão verdadeira que, praticamente, o objeto de todas as análises que fazem os neoliberais será substituir, a cada instante, o homo œeconomicus parceiro da troca por um homo 
œconomicus empresário de si mesmo, sendo ele próprio seu capital, sendo para si mesmo seu produtor, sendo para si mesmo a fonte de [sua] renda.

De acordo com Foucault (2008), o capital humano configura-se por meio dos cuidados prestados ao sujeito na infância, do nível cultural dos pais e, entre outros, dos investimentos educativos. Investimentos que tratam da instrução propriamente dita, da profissionalização dos sujeitos, do desenvolvimento de habilidades, como de comunicação, criação, inovação etc., que possam constituir um sujeito econômico ativo. O empreendedor de si, como indica Lazzarato (2017), é a completa concretização da sujeição, visto que faz do sujeito um capital, extrapolando o individualismo. Com isso, simultaneamente, impõe avaliá-lo e medi-lo nos mesmos moldes do sistema de mercado, ou seja, de ganhos e perdas, da oferta e da demanda, do investimento e da rentabilidade.

Se inovação existe, isto é, se se encontram coisas novas, se se descobrem novas formas de produtividade, se se fazem invenções de tipo tecnológico, tudo isso nada mais e que a renda de um certo capital, o capital humano, isto é, o conjunto dos investimentos que foram feitos no nível do próprio homem (FOUCAULT, 2008, p. 318).

Nessa perspectiva, tal organização configura a formação profissional de um sujeito adaptável e flexível a um sistema econômico neoliberal. Fabricação possibilitada por um capital humano que pode ser melhorado, conservado e utilizado em diversas áreas do mercado de trabalho. "O indivíduo não pode ser separado da sua capacidade para ganhar o salário; por isso, a importância de que o indivíduo aprenda e assuma a necessidade de fazer investimentos em si mesmo ao longo da vida” (LOUREIRO; LOPES, 2015, p. 333).

Sob essa lógica, o sujeito enquanto Homo cconomicus é considerado mediante o aspecto, a espécie de rede de inteligibilidade de sua conduta que "[...] faz que seja um comportamento econômico. Isso quer dizer também que o indivíduo se vai se tornar governamentalizável, que se vai poder agir sobre ele na medida em que, [...] ele é homo œconomicus" (FOUCAULT, 2008, p. 345). O trabalhador, segundo Lazzarato (2017), opera como uma empresa individual e está constantemente comprometido em negociar entre seu "eu" e o seu "supereu" econômico. 
A partir dos estudos de Foucault percebem-se alguns deslocamentos que passam a pincelar o panorama contemporâneo. Deslocamentos que reintroduzem não apenas o tema do trabalho no campo da análise econômica por meio de uma espécie de expansão ou aceleração desse (FOUCAULT, 2008).

\begin{abstract}
Nessa esteira, entende-se que a educação escolarizada, na Contemporaneidade, dada a sua relação de imanência com a sociedade, vê-se comprometida com a constituição desse tipo de sujeito cuja habilidade de fazer investimentos em si mesmo deve ser desenvolvida. Assim, acredita-se que tal ênfase acaba por provocar certo deslocamento que diferencia as funções que eram atribuídas à escola moderna daquelas que são atribuídas à escola contemporânea (LOUREIRO; LOPES, 2015, p. 333).
\end{abstract}

Em uma análise atual, Maurizio Lazzarato (2006), embebido pelos estudos de Foucault e outros autores, observa a propagação dos meios tecnológicos e os novos modos de subjetivação do sujeito, e indica modificações nas condições materiais de trabalho que implicam nas novas relações com o trabalhador, consumidor e a empresa. Segundo o autor, o trabalho assume a forma de imaterial $^{1}$ e os sujeitos (trabalhador e usuário) flexíveis, pois as próprias fronteiras serão desfeitas com o uso das tecnologias. Com isso, “[...] é sempre mais difícil distinguir o tempo de trabalho do tempo da produção ou tempo livre” (LAZZARATO; NEGRI, 2001, p. 30).

As relações nessa conjuntura são sempre exercidas numa compreensão mútua, aberta, aleatória, infinita, visto que a empresa e os sujeitos tendem a se mimetizar na livre cooperação de cérebros (LAZZARATO, 2006). Assim, é possível perceber novos processos de subjetivação que estabelecem não somente uma nova qualidade do trabalho e do lazer, mas também novas relações de poder (LAZZARATO; NEGRI, 2001).

Nota-se que o trabalho imaterial não se restringirá apenas a novas relações de produção econômica, já que implica, também, em processos de "subjetivação autônoma" 2 . O poder de gestão das informações e de tomada de decisões deve modificar as subjetividades, o que por sua vez transpassa e transforma as diversas atividades da cadeia produtiva, seja na indústria, nos serviços ou nas relações

\footnotetext{
${ }^{1}$ Para Lazzarato e Negri (2001, p. 26, grifo do autor), é "[...] uma força de trabalho social e autônoma, capaz de organizar o próprio trabalho e as próprias relações com a empresa".

2 Para Lazzarato e Negri (2001), este é entendido como "Intelectualidade de massa".
} 
ambientais (VEIGA-NETO, 2011). Observa-se que, nessa lógica, produzem mais aqueles que são dinâmicos, flexíveis, criativos e dominam o ciberespaço ${ }^{3}$. O sujeito isolado das fábricas abre cada vez mais espaço aos sujeitos interligados as redes de comunicação, cujas memórias são da empregabilidade, da disponibilidade, da docilidade às leis do mercado de trabalho e do consumo (LAZZARATO, 2011).

Ao perceber-se que o sujeito, as relações humanas e econômicas são fabricadas e transformadas na dinamicidade e no movimento das coisas do mundo, vê-se que a composição do Homo cconomicus na atualidade tem tomado artefatos que são disseminados no meio social, como os jogos eletrônicos (MADRUGA; HENNING, 2018). Loureiro (2013), embasado nas análises de Foucault e Lazzarato, pontua que a difusão das tecnologias e a promoção da inclusão digital na educação, constituem-se como modo de qualificar os sujeitos para melhores condições de empregabilidade. $\mathrm{O}$ sujeito empresário de si mesmo da atualidade é o Homo aconomicus acessibilis (LOUREIRO, 2013), o qual acrescenta a habilidade da acessibilidade e a disponibilidade, por meio da internet, para acessar e manter-se acessível. Nas palavras de Loureiro (2013, p. 175), "Sujeitos com mais acesso à educação, conectados, com acesso e disponíveis para serem acessados aumentam as possibilidades de exercício de controle".

A partir da análise desenvolvida por Loureiro (2013), entende-se que o humano acessibilis configura-se em virtude de ser fabricado por ciberespaços. Os sujeitos aprendem, ensinam, relacionam-se social e economicamente por espaços virtuais. Assim, empreende-se como capital humano, por meio de cursos à distância, vídeos on-line etc., e ao mesmo tempo cria-se o mercado do ciberespaço, os empresários/trabalhadores yybers, os youtubers. Entende-se que as peculiaridades desse conjunto de elementos potencializam a fabricação do Homo aconomicus cyber. Um humano que é inventado e reinventado para alcançar os desejos projetados por uma sociedade. Porventura não será justamente por isso que nesse tempo a ascensão mais pujante que se pode perceber é a do humano gyber?

\footnotetext{
${ }^{3}$ Segundo Lévy (2010, p. 17), "o ciberespaço é o novo meio de comunicação que surge da interconexão mundial dos computadores".
} 
Os fluxos de signos que circulam de um computador a outro em tempo real constituem uma realidade que é tão objetiva quanto os próprios fluxos materiais; eles intervêm no sistema que fixa os preços das ações e agem diretamente sobre a economia "real" e sobre as subjetividades (LAZZARATO, 2014, p. 85).

$\mathrm{Na}$ atualidade os youtubers de jogos eletrônicos ganham cada vez mais influência entre os jogadores e na própria sociedade. Ser um youtuber pode se tornar uma atividade rentável tanto para a empresa, YouTube, quanto para os sujeitos que integram uma rede de cooperação de cérebros. Para Lazzarato (2006), a dinâmica do trabalho imaterial em uma sociedade moderna implica em compor um grande cérebro coletivo, no qual os cérebros individuais tornam-se células. "A natureza da atividade dos pequenos cérebros no interior do grande cérebro social não é apenas definida pela imaterialidade, pelo intelecto, pelo cognitivo, mas pela capacidade de começar alguma coisa nova [...]" (LAZZARATO, 2006, p. 123).

A fabricação de sujeitos aptos a lidarem com as tecnologias é permeada por uma perspectiva futura do trabalhador. Segundo reportagem exibida no Jornal do Almoço, no Rio Grande do Sul (RBS TV, 2018), existe uma expectativa de que até 2030 dois bilhões de empregos serão superados e desaparecerão em razão das tecnologias. Ainda reforça que as crianças que ingressarem na escola em 2018 ao se formarem em 2030 não estarão preparadas para o mercado de trabalho.

Nessa perspectiva, ao olhar-se para as novas formas de empregabilidade da atualidade, ocupada, por exemplo, pelo sujeito youtuber, que produz e é remunerado por isso, mas não trabalha oficialmente para a empresa YouTube. Em notícia divulgada nos sites da internet, entre estes, Band (2017), foi propagado que a revista Forbes lançou uma lista dos youtubers mais bem pagos pelo site. Em primeiro lugar está o britânico Daniel Middleton de 26 anos, também conhecido como TheDiamondMinecraft, que faturou cerca de R \$ 54,3 milhões. Middleton lançou em 2012 o seu canal de games intitulado DanTDM.

\footnotetext{
A clara ruptura entre emprego e desemprego, entre trabalho assalariado e trabalho independente, foi substituída por uma espécie de 'halo' de emprego, um estado turvo em que se está ao mesmo tempo empregado e desempregado, ou empregado e independente [...]. Por outro lado, os neoliberais, apesar de explorarem a mobilidade e a flexibilidade do sistema, não querem pagar o preço disso em termos de segurodesemprego (LAZZARATO, 2014, p. 135).
} 
Os youtubers, com suas estratégias, arrebatam um público enorme de seguidores, o que rende a remuneração paga pelo site YouTube. O valor pago advém do número de visualizações realizadas nos vídeos publicados. O youtuber torna-se uma espécie de usuário/empregado, ou seja, ele não possui contrato empregatício, mas por produzir conteúdo no canal, por meio do qual fideliza um público, recebe um determinado valor em dinheiro como gratificação. Diversos produtos são divulgados por meio dos youtubers, por exemplo, o jogo Minecraft, o que, por sua vez, contribui para o aumento de usuários, vendas e lucratividade para as empresas.

Em termos de público pode-se indicar, a título de exemplo, o canal intitulado Authentic Games, que grava e divulga vídeos e gameplays do jogo Minecraft. Em 2016 o canal estava em $8^{\circ}$ lugar entre os 20 maiores canais brasileiros no YouTube (ESTADÃO, 2016). No final de 2018, ele ocupava a $6^{\circ}$ posição (BELING, 2019). Atualmente seu canal tem mais de 16 milhões de inscritos (AUTHENTICGAMES, s/d). De acordo com Mendes (2006), a filiação a uma comunidade acontece de modo sutil e é montada com base em diversas frentes, entre estas a internet se faz uma das principais. O universo dos jogos eletrônicos não é somente configurado por uma comunidade, mas por múltiplas, que podem ser encontradas em torno de tais artefatos. Nessas comunidades o jogador incorporará um conjunto de práticas, participando assim ativamente do governamento dos outros e de seu autogoverno.

\section{O cenário discursivo do mundo Minecraft}

De acordo com Lazzarato (2006), a atualidade se apresenta como um tempo de transformações incorpóreas, que com seus jingles martelam em nossas cabeças, propagam-se e entram em cada lar nos quatro cantos do planeta e assim constituem uma estratégia de conquista, captura, apreensão de cérebros e de corpos. Processo de criação e de realização de mundos que são inseparáveis de uma política de redes, fluxos e de memórias artificiais. A propagação da palavra, da percepção, da visão, dos conhecimentos, das informações e dos saberes, difunde-se em espaços de disputa e de relações de poder. 
Nessa conjuntura o Homo cconomicus cyber também é investido de uma rede discursiva que engendra mecanismos tecnológicos. Com isso, chama-se a atenção para a propagação do jogo eletrônico Minecraft em diversos artefatos digitais e não digitais.

O jogo foi criado na Suécia em 2009 pela empresa Mojang. Em 2014 a empresa Microsoft comprou a criadora do jogo. Minecraft pode ser utilizado em múltiplas plataformas digitais: Java Applets, Android, iOS, Xbox, Raspberry Pi, PlayStation, Windows Phone. Também está presente em materiais escolares, artigos para festas, livros, HQs, brinquedos e, entre muitos outros objetos produzidos, uma tabela periódica.

Minecraft é um jogo eletrônico que possui o mínimo de limitação, ou seja, possibilita ao jogador explorar o ambiente virtual de forma livre para construir e reconstruir um mundo usando apenas blocos (cubos). O jogador ao iniciar o jogo pode selecionar entre o personagem feminino (Alex) ou o masculino (Steve) para jogar.

Existem três modos de jogar o Minecraft: criativo, aventura e sobrevivência. No modo criativo, o jogador já possui todos os itens na barra de materiais para construir livremente. No modo aventura, o jogador também possui todos os itens, mas as ferramentas somente funcionam se forem utilizadas adequadamente. E no modo sobrevivência, o jogador inicia o jogo sem nada de materiais, tudo deverá ser adquirido, conforme seu progresso. Nesse modo os recursos naturais são finitos. Durante o jogo, o jogador recebe informações de seu avanço e dicas em paratextos.

Na Suécia o jogo se tornou uma disciplina obrigatória nas escolas (ALVES, 2013). Além da Suécia, o jogo Minecraft foi utilizado em salas de aula dos Estados Unidos, Irlanda e Brasil. Estima-se que mais de 40 países tem utilizado o jogo como ferramenta pedagógica (LOPES, 2016). “Além das escolas, 'Minecraft' também virou base para projetos sociais. [...] O projeto, chamado Bloco por Bloco, é coordenado pelo Habitat, escritório da ONU para desenvolvimento urbano e ambiental [...]" (ORRICO, 2013, s/p).

Em 2015 a Monsanto, uma multinacional da agricultura e da biotecnologia, promoveu um desafio em uma feira de games em São Paulo. O desafio intitulado "Desafio Fazenda Sustentável", consistia em criar "[...] no ambiente do jogo [Minecraft] uma fazenda de acordo com critérios de boas práticas na agricultura, [...], 
por exemplo, delimitar Áreas de Proteção Permanente (APP) e de Reserva Legal' (SALOMÃO, 2015, s/p, grifos do autor).

No mesmo ano, 2015, a Netflix, provedora mundial de filmes e séries via streaming, lançou uma série interativa do Minecraft. Intitulada Minecraft: story mode, a série possui cinco episódios em que o assinante pode selecionar qual ação o personagem irá seguir em determinada situação.

Outra empresa famosa pelo serviço de streaming que tem divulgado o Minecraft é o Spotify. Um serviço de streaming digital que dá acesso a músicas, podcasts, vídeos e outros conteúdos de artistas de todo o mundo. Desde 2011, com o álbum Minecraft - volume Alpha, tem lançado diversos volumes com a trilha sonora do jogo.

Com tamanha proliferação o jogo também mostrou o seu potencial como ferramenta pedagógica. E em novembro de 2016 a Microsoft cria uma versão para educação. "O interesse educacional levou os desenvolvedores do game a criar, em parceria com programadores e educadores da Finlândia e dos Estados Unidos, o projeto Minecraft.edu, para facilitar o acesso e o uso do jogo nas escolas" (ALVES, 2013, s/p). O site Gizmodo Brasil (VENTURA, 2016, s/p), ao comentar os lançamentos da Microsoft para a educação, especialmente o Minecraft: Education Edition ou MinecraftEdu (s/d), aponta que:

\footnotetext{
A diferença em relação ao jogo tradicional está em recursos adicionais para escolas: esta versão permite que professores criem e apliquem projetos para seus alunos. [...] A Microsoft tem diversas lições sugeridas, incluindo "fatores e múltiplos", "área e perímetro", "perda de biodiversidade", "desmatamento", "planejamento de cidades", entre muitas outras.
}

Em 2018 o jogo Minecraft, famoso entre crianças e adolescentes, surgiu no Exame Nacional do Ensino Médio (Enem). Ao ser citado em uma questão de matemática, a prova surpreendeu e agradou muitos estudantes que conheciam ou jogavam o jogo (FARIA, 2018).

O reflexo da grande disseminação do jogo no mundo é vislumbrado nos números divulgados que indicam um crescimento vertiginoso de usuários. De acordo com Lastowka (2011), com muita publicidade, até ao verão de 2011, a Mojang tinha vendido mais de 3 milhões de cópias do Minecraft e registrou mais de 10 milhões de usuários, atingindo assim mais de 60 milhões de dólares em receitas. Mesmo com o 
enorme sucesso, Markus "Notch" Persson, proprietário e fundador da empresa Mojang, vende o jogo para Microsoft por US\$2,5 bilhões.

Em janeiro de 2018, a chefia da Mojang divulgou no site Adrenaline os novos dados de venda do jogo Minecraft. Segundo o site (MOGNON, 2018, s/p, grifos do nosso), "[...] o jogo de bloquinhos alcançou 74 milhões de jogadores ativos e já vendeu 144 milhões de cópias mundialmente em todas as plataformas que está disponível”.

No início de 2019, o site IGN Brasil, divulgou os novos números do jogo. "Minecraft tem mais de 91 milhões de jogadores ativos mensais [...]" (LIMA, 2019, s/p, grifos nosso). Em maio do mesmo ano, para comemorar o aniversário de 10 anos do jogo, a empresa Microsoft divulgou que o mesmo vendeu 176 milhões de unidades. Com isso, segundo reportagem, "Minecraft torna-se o jogo mais vendido de sempre" (SALGADO, 2019, s/p). Tais números indicam que os usuários não param de crescer pelo mundo.

Diante desse cenário discursivo de produção do mundo Minecraft, faz-se as seguintes indagações: como o modo de se pensar a aprendizagem pode ser modelado por um discurso tecnológico e mercadológico? Que ditos atrelam-se a educação para constituir um determinado sujeito social? É o que se buscará também responder com a análise do material apresentado a seguir.

\section{Analisando as discursividades nos planos de aula}

A análise apresentada trata da forma sistemática da exterioridade, conforme ensina Foucault (2015), a descrição histórica das coisas ditas é transpassada pela oposição do interior e do exterior, comandada pelo retorno da exterioridade. Contingências ou necessidades materiais, corpo visível, que se direciona ao núcleo essencial da interioridade, o qual múltiplos sujeitos se reconhecem como parte de um dito naturalizado em verdade.

A coleta e seleção dos dados constituíram-se em um momento de trabalho constante e intenso. Ao acessar a página do MinecraftEdu (s/d), selecionou-se no menu de busca os planos destinados a faixa etária de 6 a 7 anos de idade. Como resposta da busca obteve-se 80 planos de aula. 
As lições são disponibilizadas no menu "Recursos de classe", onde entre as opções existe a que se intitula "Encontre uma lição", a qual direciona o usuário para um quadro com diversos temas. Os planos de aula trazem disponibilidade para diversas faixas etárias, mostrando uma flexibilidade para a transição de uma turma para outra.

Para refinar a busca selecionaram-se os planos que abordavam o tema "Meio Ambiente”. Após aprimorar a pesquisa na página obteve-se um total de 13 planos de aula, que correspondem aos anos de 2016 (1 lição), 2017 (3 lições) e 2018 (9 lições), o que parece apontar para uma aderência maior dos professores ao jogo como proposta pedagógica. Também se observou que a maioria dos planos indica fundamentar-se em uma aprendizagem baseada em projetos (7 lições $\left.{ }^{4}\right)$, para o desenvolvimento de habilidades como colaboração (8 lições), criatividade (7 lições), pensamento crítico (5 lições), comunicação (3 lições) e cidadania (2 lições). Cada plano indica de duas a três habilidades a serem desenvolvidas, ou seja, pode ter a seguinte apresentação: "Colaboração e Aprendizagem Baseada em Projetos” ou "Colaboração, Criatividade e Aprendizagem Baseada em Projetos". O conteúdo dos planos se entrecruza com outros temas, o que mescla o ensino do meio ambiente a outros conhecimentos.

A partir da leitura atenta dos 13 planos de aula, o material foi sendo organizado conforme os ditos emergiam. Examinou-se e reexaminou-se os excertos recortados para logo após começar a organizá-los conforme a unidade analítica a qual os remetiam. Ressalta-se que nesta proposta de pesquisa não se estipula nenhuma categoria de análise previamente. Nessa perspectiva, reuniu-se e agrupou-se os dados que emergiam do próprio material empírico. Assim, surgiram dois conjuntos de ditos que se atravessam entre eles e que constituem peculiaridades de um determinado Homo xconomicus cyber da atualidade, as quais apontam para um sujeito empresário de si e ambientalmente proativo.

$\mathrm{Na}$ análise dos ditos que apontam para um sujeito empresário de si percebeuse o empreendimento de práticas de docilização; pensamento de grupo; a fabricação de sujeitos flexíveis; criativos, dinâmicos e articulados na troca e aprimoramento de

\footnotetext{
${ }^{4}$ Em quantas lições aparecem às habilidades indicadas. 
ideias que resultem em uma resposta eficaz. "A ênfase parece estar direcionada para a aprendizagem de outras formas de comportamentos - isto é, formas de conceber a si mesmo, formas de ser, de se relacionar, de se comunicar, de consumir, competir, interagir, etc.[...]" (LOUREIRO, 2013, p. 155). Com isso, vê-se que os ditos encontrados apontam para um modo de sujeito escolarizado, conforme nota-se nos seguintes fragmentos: "Os alunos podem entender facilmente o conceito de uma ponte e por que essas estruturas são essenciais para a oferta e a demanda do mundo em que vivemos" (GOZZARD 2017, p. 2). "Nós temos nossa própria "supermente" em nossa sociedade?; Como eles conseguem fazer uma tarefa complexa sem falar?; Avaliar e testar opções para identificar a solução mais eficaz e colocar as ideias em ação; Trabalhar em colaboração com os colegas para atingir um objetivo comum" (TELFER, 2018, p. 2). "Demonstrar boas habilidades de pesquisa; Apresentar-se bem à turma mais ampla” (MINECRAFTEDU, 2018, p. 2).

Colocando de forma mais enfática, a capacidade de empresariar a si mesmo talvez seja uma das principais habilidades que o sujeito contemporâneo precisa aprender, o mais cedo possível, para poder se manter em condições de empregabilidade. Em alguns casos, essa capacidade pode se tornar uma necessidade para driblar a falta de vagas de trabalho, já que, na Contemporaneidade, o trabalhador passa a ser o seu próprio capital (LOUREIRO, 2013, p. 145).

Nota-se que a educação escolarizada neste tempo, por estar diretamente relacionada com a sociedade, entende-se comprometida com a constituição de sujeitos cujas habilidades de fazer investimentos em si mesmos devem ser em todo momento potencializado (LOUREIRO, 2013). Formar capital humano, segundo Foucault (2008, p. 315),

Formar, portanto, essas espécies de competência-máquina que vão produzir renda, ou melhor, que vão ser remuneradas por renda, quer dizer o que? Quer dizer, e claro, fazer o que se chama de investimentos educacionais. Na verdade, não se esperaram os neoliberais para medir certos efeitos desses investimentos educacionais, quer se trate da instrução propriamente dita, quer se trate da formação profissional, etc. Mas os neoliberais observam que, na verdade, o que se deve chamar de investimento educacional, em todo caso os elementos que entram na constituição de um capital humano, são muito mais amplos, muito mais numerosos do que o simples aprendizado escolar ou que o simples aprendizado profissional. 
A constituição de sujeitos dinâmicos e flexíveis se fundamenta num pensamento neoliberal, computacional e científico para a resolução de futuras situações problemas, entre tais, as provocadas por uma crise ambiental. Com isso, ditos apontam para as habilidades necessárias aos sujeitos da atual sociedade: "a oferta e a demanda do mundo" (GOZZARD 2017, p. 2); “Avaliar e testar”, “identificar a solução mais eficaz e colocar as ideias em ação", "supermente em nossa sociedade", "fazer uma tarefa complexa sem falar", "trabalhar em colaboração" (TELFER, 2018, p. 2); "boas habilidades de pesquisa" , "Apresentar-se bem" (MINECRAFTEDU, 2018, p. 2).

\footnotetext{
Se os capitalistas podem falar de "capital humano" em uma segunda acepção, é porque nada do que é "humano" escapa às servidões maquínicas, aos dispositivos tecnossemióticos, aos laboratórios científicos e às indústrias que os exploram. Se nós todos, sem distinção, somos constituídos por "capital humano", é porque nós todos, sem distinção, constituímos componentes, "entrada" e "saída" de redes tecnossemióticas, mesmo e sobretudo quando estamos desempregados, em formação e aposentados (LAZZARATO, 2017, p. 176-177).
}

O Homo æconomicus, afirma Foucault (2008), é aquele que aceita a realidade, assim, no que se refere aos ditos do material, o real é compreendido como um tempo de crise ambiental. Com isso, a conduta racional é qualquer comportamento que seja sensível a modificações nas variáveis do ambiente e que lhes responda de forma, portanto, sistemática, e a economia vai então poder ser caracterizada como a ciência da sistematicidade das respostas às variáveis do meio (FOUCAULT, 2008). Com isso, passa-se para a segunda recorrência encontrada no material.

$\mathrm{Na}$ medida em que emergiam os ditos de um sujeito empresário de si também surgiam de um sujeito ambientalmente proativo e assim iam mesclando-se na fabricação do Homo economicus yyber. Por meio da tecnologia de simulação, estratégias são desenvolvidas para prevenir, resolver, aprimorar e elaborar ideias inteligentes e ambientalmente responsáveis. Um sujeito proativo ambientalmente que assume uma visão científica e tecnológica para efetuar ações bem-sucedidas no mundo. Lazzarato (2017, p. 196), considerando a observação de Foucault, aponta que "[...] a governamentalidade é capaz de preparar um meio, incitando-o [o sujeito] a responder 'automaticamente' às variações sistêmicas”. 
Visando um amanhã sustentável e uma vida integrada à natureza, cria técnicas avançadas para a produção da horta, desenvolve habilidades com as plantas, prevê os impactos da ação do humano no meio ambiente, projeta cidades, bairros em que a natureza boa faça parte do que é saudável para o humano. "O saber ambiental olha assim a dispersão do discurso da sustentabilidade e das posições subjetivas que sustentam suas narrativas" (LEFF, 2001, p. 197).

Nisso cita-se alguns excertos que possibilitam perceber como vai se constituindo uma visão de crise ambiental: "Aplicar princípios científicos para projetar um método de monitoramento e minimização do impacto humano no meio ambiente; Você é um oficial do bem-estar da vida selvagem para uma ONG internacional; Expressar empatia pelo assunto em questão” (MINECRAFTEDU, 2018 , p. 3). "Reconhecer as mudanças que as pessoas fizeram no meio ambiente ao longo do tempo; Investigue o que pode ser feito para conservar e promover a biodiversidade; Investigar o impacto do conflito entre as necessidades sociais, econômicas e ambientais, tanto local quanto globalmente, por exemplo, perda de biodiversidade, mudança climática, desmatamento" (PHILLIPS, 2018, p. 2). "As florestas estão mais do que nunca precisando de proteção para manter não apenas sua diversidade biológica, mas também porque elas são o fator de limpeza de ar mais importante em nosso globo, além dos oceanos. [...] com os efeitos óbvios da mudança climática, a falta de planejamento territorial rural e florestal, infraestruturas rodoviárias e ferroviárias, bem como assentamentos humanos, o risco de incêndios florestais e a vulnerabilidade das florestas atingiram agora um nível além do qual comprometer seriamente esses ecossistemas e sua gestão sustentável” (FERREIRA, 2018, p. 2). “Os alunos irão aprofundar seus conhecimentos sobre alimentação saudável através do plantio de sementes" (TURNER, 2018, p. 2).

No material outros ditos foram apontados, mas os ditos de práticas pontuais pautadas no discurso de crise ambiental são os que mais se destacam nas lições. Mesclado a tal discurso encontram-se os ditos de uma educação para o desenvolvimento sustentável, os quais expressam, conforme sustenta Leff (2001), estratégias conflitivas que correspondem a visão e a interesses diferenciados. Propostas que atravessam o neoliberalismo ambiental e a construção de uma racionalidade produtiva. Em uma perspectiva economicista o livre mercado possui 
preferência como mecanismo para interiorizar as externalidades ambientais e valorizar a natureza, pois recodifica a ordem da vida e da cultura, especialmente, no que tange a um capital natural e humano.

Com isso, nota-se que os planos anunciam a implementação de condutas ambientalmente corretas, ou ainda, para práticas de desenvolvimento sustentável, agora pensadas e antecipadas de modo inteligente por meio da simulação, produção e análise de dados. "A sujeição social intervém sobre o corpo por meio do espaço, bem como pelo viés das leis, dos saberes especializados, das normas, das semióticas linguísticas e visuais e do sistema educativo, como Foucault nos ensinou" (LAZZARATO, 2017, p. 187).

Somos tensionados a todo o momento a participar de algum modo dessa "grande catástrofe ambiental", que acomete a todos. Desse modo, nossas ações individuais e coletivas vão sendo reguladas, controladas e conduzidas cotidianamente. Um novo sujeito passa a ser produzido a partir desses ditos e jogos de força operacionalizados em diversas instâncias sociais (GARRÉ; HENNING, 2015, p. 55).

Como indicado anteriormente, a educação está diretamente relacionada com as demandas da sociedade, por isso os ditos que pronunciam a crise ambiental também produzem demandas para a escola. "E, esses ditos, ao circularem e se reverberarem vão nos convidando a participar desta rede discursiva, vamos sendo convidados a ver e a falar sobre a problemática ambiental" (GARRÉ; HENNING, 2015, p. 67).

No que se referem as práticas desenvolvidas nas lições vê-se que, conforme denuncia Leff (2001), a educação para o desenvolvimento sustentável demanda novas orientações e conteúdos, outras práticas pedagógicas, onde estas sejam organizadas na relação de produção de conhecimentos, de problematização do próprio pensamento, de exposição e disseminação do saber ambiental.

Com isso, a constituição de um Homo cconomicus cyber passa pela proliferação de ditos de sujeitos empresários de si e proativos ambientalmente. Um sujeito que aprende e propaga a relevância de cada um, faz " [...] investimentos em si mesmo; que aproveite [...] para desenvolver a educação em todos os espaços; que desenvolva habilidades como criatividade, autonomia, cooperação, comunicação; e que aumente o seu potencial de empregabilidade" (LOUREIRO; LOPES, 2015, p. 338). 


\section{Considerações finais}

A possibilidade que se buscou abrir com tal pesquisa é de, minimamente, romper com os discursos circulantes, com as verdades dadas, com as certezas mais firmes, para, com isso, potencializar resistências aos processos discursivos que subjetivam, modelam e conduzem sujeitos.

Ao analisar os planos de aula para crianças de 6 a 7 anos com o tema Meio Ambiente, evidenciou-se que os ditos que circulam na atualidade passam a atravessar a escola. Com isso, mobiliza professores, interpelados por ditos, a colocar em debate, ensinar e utilizar modos inovadores na aprendizagem da dita crise ambiental que tanto bate à porta e inquieta a mente de muitos. Bem como, para a constituição de um sujeito empresário de si, que por ser flexível e dinâmico adapta-se a novas condições de empregabilidades.

Percebeu-se que no cenário discursivo desse tempo a constituição de um humano com habilidades tecnológicas voltadas a sanar as demandas sociais, ambientais e econômicas, também é assumida pela escola. Fabricação que passa pela escolarização dos primeiros anos, visto que parece ser necessário potencializar o mais cedo possível um modelo de Homo cconomicus cyber. No entanto, ressalta-se que tal fabricação não está reduzida apenas ao espaço escolar, mas sim a toda uma sociedade que projeta modos de vida dos sujeitos. Somos todos interpelados pelas verdades desse tempo!

Por fim, compreende-se que existem outros tantos temas latentes nesse tempo que poderiam e deveriam receber atenção. $\mathrm{Na}$ seleção dos materiais observou-se que no quadro de lições do MinecraftEdu constava planos de aula para a educação especial e para crianças de 3 a 5 anos. No âmbito da educação temas como esses são caros, pois trazem as inúmeras problemáticas que impactam o campo. Com isso, fica o seguinte questionamento: realmente é possível trabalhar tais temas em um jogo eletrônico? A partir desta problematização, entende-se que mais olhares poderiam ser lançados sobre tal material, visto que se faz relevante tensionar o que se diz e o que fazem dizer sobre o uso das tecnologias na educação. 


\section{Referências}

ALVES, L. Game usado por professores vira febre entre crianças e adolescentes. Diário Gaúcho, Porto Alegre, 23 fev. 2013. Disponível em: http://m.diariogaucho. com.br/noticias/todas/a4053234. Acesso em: 30 jun. 2017.

AUTHENTICGAMES. Disponível em: https://www.youtube.com/user/ AuthenticGames. Acesso em: 18 jan. 2019.

BAND. Revista Forbes divulga lista dos dez youtubers que mais arrecadaram em 2017. Bandnews TV, 9 dez. 2017. Disponível em: http://videos.band.uol.com.br/16364601/revista-forbes-divulga-lista-dos-dez-youtubersque-mais-arrecadaram-em-2017.html. Acesso em: 10 dez. 2017.

BELING, F. Os 10 maiores canais do YouTube. . Oficina da Net, atualizado em 20 nov. 2019. Disponível em: https://www.oficinadanet.com.br/post/13911-os-10-maiores-canaisdo-youtube. Acesso em: 27 fev. 2019.

GOZZARD, C. The strongest bridge. Minecraft Education Edition: Homepage, 27 fev. 2017. Disponível em: https://education.minecraft.net/user/cynthia-gozzard. Acesso em: 21 nov. 2018.

DEVIANTART. Tabela Periódica do Minecraft, 2016. Disponível em: https://www.deviantart.com/caio202/art/Tabela-periodica-do-minecraft-601507911. Acesso em: dez. 2019.

ESTADÃO. Os 20 maiores canais brasileiros no YouTube. Estadão 2016. Disponível em: https://link.estadao.com.br/galerias/geral,os-20-maiores-canais-brasileiros-noyoutube, 27560. Acesso em: 7 fev. 2019.

FARIA, L. Enem 2018 tem questão relacionada ao jogo Minecraft. Veja, 11 nov. 2018. Disponível em: https://veja.abril.com.br/educacao/enem-2018-tem-questao-relacionadaao-jogo-minecraft/. Acesso em: 30 dez. 2018.

FISCHER, R. M. B. Trabalhar com Foucault. arqueologia de uma paixão. Belo horizonte: Autêntica Editora, 2012.

FERREIRA, F. Forest/rural fires. Minecraft Education Edition: Homepage, 23 ago. 2018. Disponível em: https://education.minecraft.net/user/Filipeferreira@colegiocasamae.pt. Acesso em: 21 nov. 2018.

FOUCAULT, M. O nascimento da biopolitica. São Paulo: Martins fontes, 2008.

FOUCAULT, M. A arqueologia do saber. 8. ed. Rio de Janeiro: Forense Universitária, 2015.

GARRÉ, B. H.; HENNING, P. C. Visibilidades e Enunciabilidades do Dispositivo da Educação Ambiental: A Revista Veja em Exame. Alexandria - Revista de Educação em Ciência e Tecnologia, Campina, v. 8, n. 2, p. 53-74, jun. 2015.

LAZZARATO, M.; NEGRI, A. Trabalho imaterial. Rio de Janeiro: DP\&A, 2001.

LAZZARATO, M. As revoluções do capitalismo. Rio de Janeiro: Civilização Brasileira, 2006. 
LAZZARATO, M. O governo das desigualdades: crítica da insegurança neoliberal. São Carlos: Edufscar, 2011.

LAZZARATO, M. Signos, Máquina, subjetividades = Signes, machines, subjectivités. São Paulo: Edições Sesc: N-1 edições, 2014.

LAZZARATO, M. O governo do homem endividado. São Paulo: N-1 edições, 2017.

LASTOWKA, G. Minecraft as Web 2.0: Amateur Creativity \& Digital Games. Social Science Research Network - SSRN, out. 2011. Disponível em: http://dx.doi.org/10.2139 /ssrn.1939241. Acesso em: 7 dez. 2016.

LÉVY, P. Cibercultura. 3. ed. São Paulo: Editora 34, 2010.

LEFF, E. Saber ambiental: sustentabilidade, racionalidade complexidade, poder. Petrópolis: Rio de Janeiro: Vozes, 2001.

LIMA, D. Minecraft tem mais jogadores mensalmente do que Fortnite. IGN Brasil, 11 jan. 2019. Disponível em: https://br.ign.com/minecraft/69936/news/minecraft-tem-maisjogadores-mensalmente-do-que-fortnite. Acesso em: 30 jan. 2019.

LOPES, M. Versão educativa do Minecraft chega à sala de aula. Porvir, 19 jan. 2016. Disponível em: http:// porvir.org/versao-educativa-minecraft-chega-a-sala-de-aula/. Acesso em: 9 abr. 2016.

LOUREIRO, C. B. Disseminação das tecnologias digitais e promoção da inclusão digital na Educação Pública: estratégias da governamentalidade eletrônica. 210f. 2013. Tese (Doutorado em Educação) - Universidade do Vale do Rio dos Sinos, Unisinos, São Leopoldo, 2013.

LOUREIRO, C. B.; LOPES, M. C. A promoção da inclusão digital e a constituição do Homo œconomicus accessibilis. Educação, Porto Alegre, v. 38, n. 3, p. 329-339, set./dez. 2015. Disponível em: http://revistaseletronicas.pucrs.br/faced /ojs/index.php/faced/article/viewFile/21772/14085. Acesso em: 20 maio 2019.

MADRUGA, E. B.; HENNING, P. C. O governamento do medo como tática de educação ambiental nos jogos eletrônicos. Revista Teias, [S.l.], v. 19, n. 53, p. 345-357, jul. 2018. Disponível em: https://www.e-publicacoes.uerj.br/index.php/revistateias /article/view/32816. Acesso em: 28 jan. 2019.

MENDES, C. L. Jogos eletrônicos: Diversão, poder e subjetivação. Campinas: Papirus, 2006.

MINECRAFTEDU. Education Edition: Homepage. Disponível em: https://education. minecraft.net/. Acesso em: 27 nov. 2018.

MINECRAFT EDUCATION EDITION. Running with rhinos. Homepage, 22 abr. 2018. Disponível em: https://education.minecraft.net/user/MEEAdmin. Acesso em: 21 nov. 2018.

MOGNON, M. Minecraft alcança a marca de 74 milhões de jogadores ativos, revela Mojang. Adrenaline, 22 jan. 2018.2 Disponível em: https://adrenaline.uol.com.br/2018/01/22/53980/minecraft-alcanca-a-marca-de-74-milhoes-dejogadores-ativos-revela-mojang/. Acesso em: 22 jan. 2018. 
NETFLIX. Série interativa: Minecraft Story Mode. Disponível em: https://www. netflix.com/br/title/80227995. Acesso em: 10 jan. 2019.

ORRICO, A. Game 'Minecraft' é adotado como ferramenta de ensino por quase mil escolas no mundo. Folha de São Paulo, São Paulo, 21 jan. 2013. Disponível em: http://www1.folha.uol.com.br/tec/2013/01/1217130-game-minecraft-e-adotado-comoferramenta-de-ensino-por-quase-mil-escolas-no-mundo.shtml. Acesso em: 9 abr. 2016.

PHILLIPS, C. Tropical ravine world. Minecraft Education Edition: Homepage, 14 nov. 2018. Disponível em: https://education.minecraft.net/user/clark-phillips. Acesso em: 21 nov. 2018.

RBS TV. Professor de Santa Maria cria projeto para inserir computação desplugada no ensino básico. Jornal do Almoşo, RBS TV, Santa Maria, 4 abr. 2018. Disponível em: http://g1.globo.com/rs/rio-grande-do-sul/jornal-do-almoco/videos/t/edicoes/v/ professor-de-santa-maria-cria-projeto-para-inserir-computacao-desplugada-no-ensinobasico/6634970/. Acesso em: 7 ago. 2018.

SALGADO, J. Minecraft torna-se no jogo mais vendido de sempre. Eurogamer, 18 maio 2019. Disponível em: https://www.eurogamer.pt/articles/2019-05-18-minecraft-torna-se-nojogo-mais-vendido-de-sempre. Acesso em: 26 maio 2019.

SALOMÃO, R. Jogadores terão desafio de criar fazenda virtual sustentável. Revista Globo Rural, São Paulo, 17 out. 2015. Disponível em: http://revistagloborural.globo.com/Noticias/noticia/2015/10/jogadores-terao-desafio-decriar-fazenda-virtual-sustentavel.html. Acesso em: 10 abr. 2016.

SPOTIFY. Minecraft - Volume Alpha. Disponível em: https://open.spotify .com/album/3Gt7rOjcZQoHCfnK15AkK7. Acesso em: 10 jan. 2019.

TELFER, L. Bees! bees! bees! be a bee! Minecraft Education Edition: Homepage, 8 dez. 2018. Disponível em: https://education.minecraft.net/user/lynne-telfer. Acesso em: 21 nov. 2018.

TURNER, A. Healthy eating lesson. Minecraft Education Edition: Homepage, 26 mar. 2018. Disponível em: https://education.minecraft.net/user/andy-turner. Acesso em: 21 nov. 2018.

VEIGA-NETO, A. Governamentalidades, neoliberalismo e educação. In: CASTELO BRANCO, G.; VEIGA-NETO, A. (org.). Foucault. filosofia \& política. Belo Horizonte: Autêntica Editora, 2011.

VENTURA, F. Microsoft oferece Office com novos recursos para alunos e professores no Brasil. Gižmodo Brasil, 28 out. 2016. Disponível em: http://m.gizmodo.uol.com.br/microsoft-classroomminecraft-brasil/. Acesso em: 29 out. 2016.

RECEBIDO: $14 / 03 / 2019$

APROVADO: $15 / 10 / 2019$
RECEIVED: 03/14/2019

APPROVED: $10 / 15 / 2019$
RECIBIDO: $14 / 03 / 2019$

APROBADO: $15 / 10 / 2019$ 